\title{
DIAGNÓSTICO FLORÍSTICO DA PRAÇA FLORIANO PEIXOTO NA CIDADE DE MACAPÁ, AMAPÁ
}

\author{
FLORISTIC DIAGNOSTIC OF FLORIANO PEIXOTO SQUARE IN MACAPÁ CITY, \\ AMAPÁ
}

\author{
Adelson Rocha Dantas ${ }^{1}$, Ediellen Mayara Corrêa Gomes², Angélica Pantoja Pinheiro³
}

\section{RESUMO}

O estudo teve como objetivo realizar um diagnóstico quali-quantitativo da arborização da praça Floriano Peixoto, na cidade de Macapá-AP. Foram mensurados as CAP's e as alturas das árvores e das palmeiras, e determinados os parâmetros fitossociológicos, distribuição diamétrica e classes de altura da composição florística. As espécies ornamentais foram identificadas. Foram encontrados 240 indivíduos (palmeiras e árvores), distribuídos em 10 famílias, 18 gêneros e 19 espécies. As famílias que se destacaram com maior número de espécies foram Arecaceae e Fabaceae com quatro espécies cada. Euterpe oleracea Mart. dominou em número de indivíduos (86 indivíduos). As espécies que obtiveram maior índice de valor de cobertura foram: Clitoria fairchildiana R.A. Howard (46,35\%), Mangifera indica L. $(39,20 \%)$ e Euterpe oleracea (36,94\%). O índice de diversidade ( $\left.H^{\prime}\right)$ obtido foi 0,98 . A estrutura diamétrica apresenta conformação de "J invertido". A maioria dos indivíduos, árvores e palmeiras, apresentam altura acima de $6 \mathrm{~m}$. Foram encontradas nove famílias de espécies ornamentais, divididas em 11 gêneros e 12 espécies, sendo maioria exóticas. Os resultados sugerem medidas que visem o planejamento adequado da diversificação florística e valorização da flora local na arborização da Praça Floriano Peixoto. Essas medidas podem ser adotadas para outras praças de Macapá.

Palavras-chave: Áreas verdes públicas; Planejamento urbano; Inventário florístico urbano; Parâmetros fitossociológicos; Espécies exóticas.

\section{ABSTRACT}

The study aimed to carry out a qualitative-quantitative diagnosis of Floriano Peixoto Square's afforestation, in the Macapá-AP city. There were measured the CBH's and the heights of the trees and palms, and determined the phytosociological parameters, diameter distribution and height classes of floristic composition. Ornamental species were identified. There were found 240 individuals (palms and trees), distributed in 10 families, 18 genera and 19 species. The families that stood out with higher number of species were Arecaceae and Fabaceae with four species each. Euterpe oleracea Mart. dominated in number of individuals (86 individuals). The species that had higher IVC were: Clitoria fairchildiana R.A. Howard (46.35\%), Mangifera indica L. (39.20\%) and Euterpe oleracea (36.94\%). The diversity index obtained was 0.98 . The diametric structure presents conformational of "inverted J". Most individuals, trees and palms, have a height above $6 \mathrm{~m}$. Nine families of ornamental species were found, divided in 11 genera and 12 species, most are exotic. The results suggest measures to the proper planning of the floristic diversity and valorization of local flora in afforestation of Floriano Peixoto Square. These measures can be adopted for other squares of Macapá.

Keywords: Public green areas; Urban planning; Urban floristic inventory; Phytosociological parameters; Exotic species.

Recebido em 25.10.2016 e aceito em 20.12.2016

1 Engenheiro Florestal, MSc., Doutorando do PPG em Ecologia do Instituto Nacional de Pesquisas da Amazônia. Manaus/AM Email: adelson.dantas@yahoo.com.br

2 Engenheira Florestal, MSc., Universidade Federal do Espírito Santo. Vitória/ES Email: ediellengomes@yahoo.com.br

3 Estudante do curso de Engenharia Florestal, Universidade do Estado do Amapá. Macapá/AP Email: angelpantoja15@hotmail.com 


\section{INTRODUÇÃO}

As cidades vivem em um contínuo processo de crescimento e expansão, sendo atrativas para um contingente cada vez maior de pessoas, por permitirem o acesso a diversos bens e serviços. São constituídas, do ponto de vista físico, por áreas construídas e por espaços livres de construção (BARBOSA; LOPES; LOPES, 2015).

O crescimento e o desenvolvimento acelerado das cidades transformaram totalmente a paisagem natural. Estas alterações, principalmente de origem antrópica, provocam a supressão da vegetação urbana, cedendo lugar para as edificações, pavimentação asfáltica, entre outros elementos da malha urbana. A vegetação urbana é considerada um fator de vital importância, não só pelo seu valor estético, mas também pelo seu papel ecológico (serviços ecossistêmicos) desempenhado na melhoria das condições ambientais da cidade (SANTOS; JOSÉ; SOUSA, 2013). Segundo Oliveira et al. (2013), o aumento do índice de qualidade ambiental nas cidades está relacionado com o aumento das áreas livres verdes. Dentre as categorias de áreas verdes, destacam-se as praças que possuem importante papel no meio urbano.

Atualmente, a definição de praça pode ser descrita como sendo espaços públicos urbanos livres de edificações (áreas verdes) que tem a função de promover convivência sadia à população, oferecendo recreação e bem-estar ambiental, além de buscar a democratização do acesso ao esporte e ao lazer, o incentivo a inclusão social e a expressão cultural. Um município ao oferecer à sua população um espaço público qualificado, propicia um ambiente saudável de convivência comunitária (ALCANTARA; VAZQUEZ, 2016).

A arborização de praças é um assunto que tem crescido em importância nas discussões sobre os problemas das cidades e na busca de maior qualidade de vida para o cidadão. A gestão de espaços públicos verdes requer profissionais capacitados e habilitados, pois o planejamento desses espaços requer conhecimento de áreas da Botânica, Fisiologia Vegetal, Administração, etc. Não basta apenas plantar árvores, pois são inúmeros os problemas resultantes do mau planejamento ou da manutenção equivocada da arborização.

Praças arborizadas proporcionam muitos benefícios para a população da cidade, destacando-se: os benefícios estéticos (cores; texturas; e formas e impulsionam o ser humano para bem-estar); traz melhorias climáticas e ambientais (melhora o microclima, equilibrando a temperatura, graças à sombra e a evapotranspiração das árvores). Sem falar nos efeitos psicológicos (anti-estresse), fisiológicos, econômicos (agregando valor às propriedades) e sociais.

O planejamento dos limites verdes urbanos colabora para o avanço da qualidade de vida, pois uma cidade arborizada ajusta um mais perfeito equilíbrio do meio ambiente urbano, 
trazendo como benefício a melhoria da qualidade de vida das populações adjuntas. Neste contexto, o inventário florístico das áreas verdes urbanas é fundamental para o ordenamento paisagístico desses ambientes, pois, segundo Lacerda et al. (2013), o inventário facilita o bom planejamento e as tomadas de decisões por parte da gestão pública. Segundo Kramer e Krupek (2012), é fundamental conhecer a flora urbana local, isso facilita desenvolver planos de arborização que priorizem os aspectos paisagísticos e ecológicos com a valorização de espécies da flora nativa.

O objetivo deste estudo foi realizar um diagnóstico quali-quantitativo da arborização da Praça Floriano Peixoto na cidade de Macapá-AP para fornecer subsídios e suporte para bom planejamento da arborização de praças da cidade.

\section{MATERIAL E MÉTODOS}

\section{Caracterização da Área}

A Praça Floriano Peixoto está localizada no Bairro do Trem, área urbana da cidade de

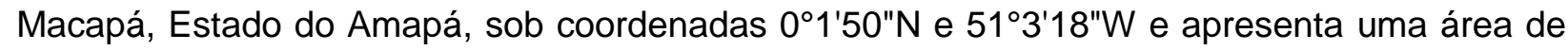
aproximadamente 23.319,84 $\mathrm{m}^{2}$ (Figura 1). O clima de Macapá, segundo Tavares (2014), é Am, megatérmico úmido com curta estação seca e temperatura média anual $26,5{ }^{\circ} \mathrm{C}$.

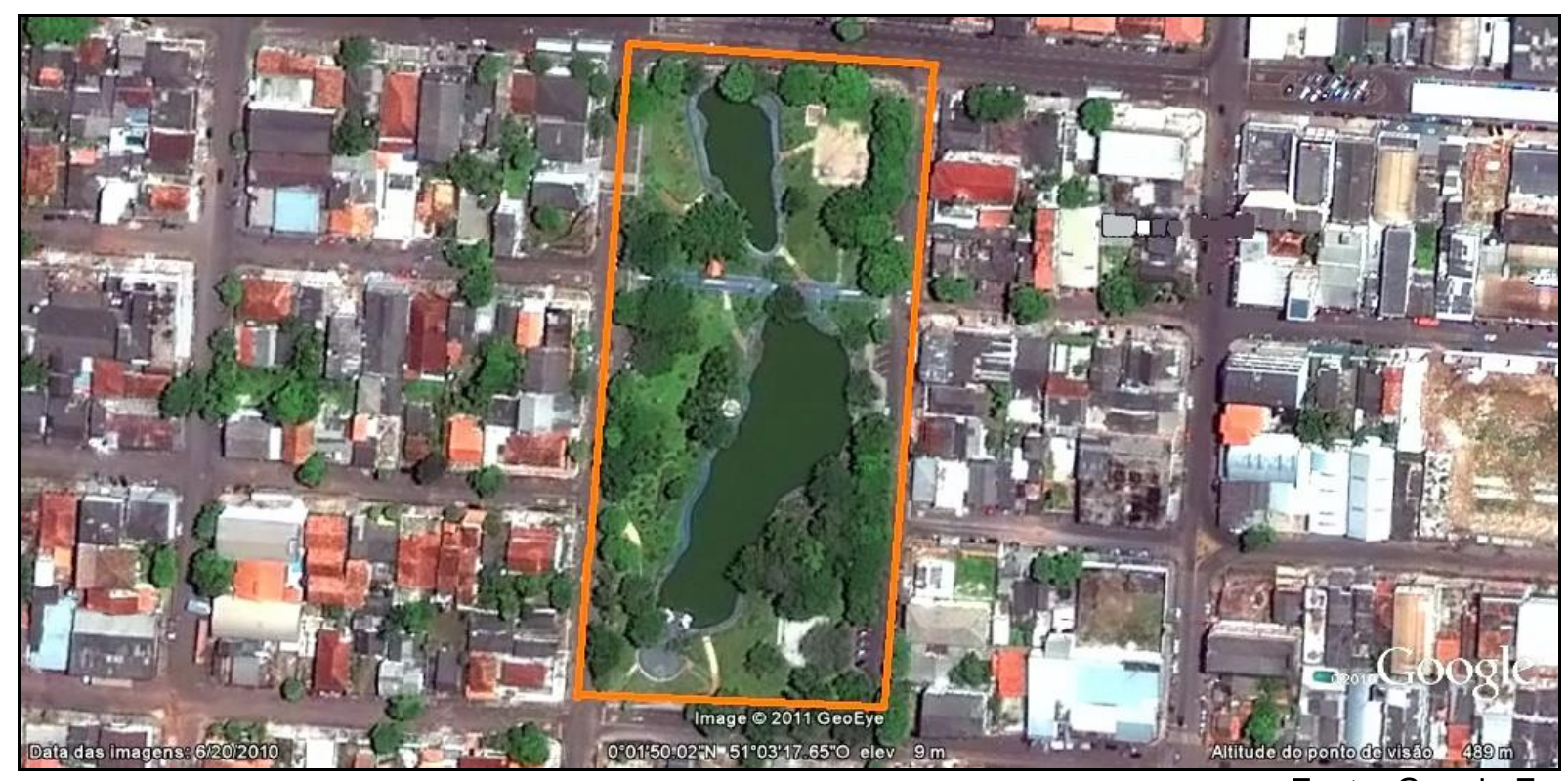

Figura 1. Vista aérea da praça Floriano Peixoto no Bairro do Trem, Macapá, Amapá Fonte: Google Earth.

Figure 1. Aerial view of Floriano Peixoto square in Trem Neighborhood, Macapá, Amapá 


\section{Coleta de dados}

Para a coleta de dados foi utilizado o método de inventário de caráter qualiquantitativo, do tipo censo, também denominado inventário total ou inventário 100\%. Foram inventariados todos os indivíduos arbóreos e não arbóreos (palmeiras) (GOMES et al., 2016). Todos os indivíduos tiveram suas alturas e CAP's (Circunferências à Altura do Peito) mensuradas, sendo que a altura foi estimada pela técnica de superposição de ângulos iguais e a CAP foi mensurada com fita métrica. Segundo Silva e Neto (1979), a técnica de superposição de ângulos iguais consiste em comparar a altura conhecida de um objeto para determinar a altura da árvore. Para isso, coloca-se uma baliza de $1 \mathrm{~m}$ de comprimento perto da árvore. Com os braços esticados e segurando um lápis, o observador se afasta da árvore de modo que o comprimento do lápis coincida com os extremos da baliza. A altura da árvore é estimada pela multiplicação do número de vezes que o lápis foi elevado pela altura da baliza.

Além da CAP e da altura foram coletados os seguintes parâmetros quali-quantitativos dos indivíduos: nome popular; família botânica; nome científico; origem fitogeográfica (nativa ou exótica); forma de vida (1-árvore ou 2-palmeira); presença ou ausência de área de desenvolvimento radicular (classificado em: (a) área pequena - quando o espaçamento é insuficiente para o desenvolvimento em largura do tronco - e (b) área suficiente - quando o espaçamento é suficiente para o desenvolvimento do tronco); ausência ou presença de cinta de proteção; e aspectos fitossanitários (presença de fungos, insetos, epífitas ou parasitas e entre outros organismos causadores de malefícios à arborização).

Embora árvores e palmeiras fazerem parte da ornamentação da praça, neste estudo consideramos espécies ornamentais sendo aquelas plantadas em canteiros e jardins da praça, que possuem função estética devido apresentarem variadas formas e coloração de folhas e flores, que embelezam a praça, e possuem aspecto herbáceo. As espécies ornamentais foram apenas identificadas, devido estarem distribuídas em agrupamentos densos e apresentarem grande número de indivíduos, tornando-se inviável a mensuração da CAP e da altura.

\section{Análise dos dados}

Os indivíduos foram identificados com auxílio de literaturas especializadas, além de consultas nos herbários on-line do Neotropical Herbarium Specimens e Missouri Botanical Garden. As espécies foram agrupadas em suas respectivas famílias botânicas de acordo com Angiosperm Phylogeny Group III - APG III (2009).

Foram calculados os seguintes parâmetros fitossociológicos: Densidade Relativa (DR); Dominância Relativa (DoR), Área Basal (AB); Índice de Valor de Cobertura (IVC) e Índice de 
Diversidade de Shannon-Weaver ( $\left.\mathrm{H}^{\prime}\right)$. Os parâmetros foram calculados pelas seguintes fórmulas:

$$
\begin{aligned}
& \text { DR }=\left(\frac{n_{i}}{n_{t}}\right) \times 100 \\
& \text { DoR }=\left(\frac{\sum g_{i}}{A B}\right) \times 100 \\
& \text { AB }=\sum g_{i} ; g_{i}=\frac{\pi \cdot D^{2}}{4} \\
& \text { IVC }=\text { DR }+ \text { DoR } \\
& \mathbf{H}^{\prime}=-\sum \mathrm{p}_{i}
\end{aligned}
$$

Onde: $\mathrm{DR}=$ densidade relativa; $\mathrm{n}_{\mathrm{i}}=$ número de indivíduos da espécie $\mathrm{i} ; \mathrm{n}_{\mathrm{t}}=$ número total de indivíduos da amostra; DoR = dominância relativa; $g_{i}=$ área basal do indivíduo da espécie $\mathrm{i} ; \sum \mathrm{g}_{\mathrm{i}}$ = somatório da área basal dos indivíduos da espécie i; $A B=$ área basal total dos indivíduos da espécie i; DAP = diâmetro à altura do peito; IVC = índice de valor de cobertura; $H^{\prime}$ = índice de diversidade de Shannon-Weaver; e $\mathrm{p}_{\mathrm{i}}=$ somatório da proporção de indivíduos da espécie i;

Os indivíduos foram agrupados em quatro classes de alturas, de acordo com os seguintes estágios de desenvolvimento vertical (SANTOS; TEIXEIRA, 2001): muda: < $1 \mathrm{~m}$; pequeno porte: > 1 a $3 \mathrm{~m}$; médio porte: > 3 a $6 \mathrm{~m}$; e grande porte: > $6 \mathrm{~m}$. O número de classes diamétricas e suas amplitudes foram definidas pela seguinte fórmula de Sturgens:

$$
\mathrm{NC}=1+3,333 \cdot \log (\mathrm{NT})
$$

Onde: $\mathrm{NC}$ = número de classes diamétricas; e NT = número total de indivíduos da amostra.

Os parâmetros fitossociologicos, a distribuição diamétrica e as classes de altura foram determinados para os indivíduos classificados como árvores e palmeiras, sendo que para as plantas ornamentais não foi possível determinar devido a questão esclarecida anteriormente.

\section{RESULTADOS E DISCUSSÃO}

\section{Composição florística}

$\mathrm{Na}$ Praça Floriano Peixoto foram encontrados 240 indivíduos, distribuídos em 10 famílias, 18 gêneros e 19 espécies. As famílias que se destacaram com maior número de espécies foram Arecaceae e Fabaceae com quatro espécies cada, seguido da família Myrtaceae com três espécies e Anacardiaceae com duas espécies. As famílias Bignoniaceae, Chrysobalanaceae, Combretaceae, Malvaceae, Moraceae e Rubiaceae apresentaram apenas uma espécie cada (Tabela 1). 
Tabela 1. Composição florística da Praça Floriano Peixoto na cidade de Macapá-AP

Table 1. Floristic composition of Floriano Peixoto square in the city of Macapá-AP

\begin{tabular}{|c|c|c|c|c|}
\hline Família & Nome Científico & Nome Comum & FV & OR \\
\hline \multirow{2}{*}{ Anacardiaceae } & Mangifera indica L. & Mangueira & 1 & $\mathrm{E}$ \\
\hline & Anacardium occidentale L. & Cajueiro & 1 & $\mathrm{~N}$ \\
\hline \multirow{4}{*}{ Arecaceae } & Euterpe oleracea Mart. & Açaizeiro & 2 & $\mathrm{~N}$ \\
\hline & Cocos nucifera L. & Coqueiro & 2 & $\mathrm{E}$ \\
\hline & Mauritia flexuosa L. f. & Buriti & 2 & $\mathrm{~N}$ \\
\hline & Roystonea oleracea (Jacq.) O.F. Cook & Palmeira-imperial & 2 & $\mathrm{E}$ \\
\hline Bignoniaceae & $\begin{array}{l}\text { Tabebuia aurea (Silva Manso) Benth. \& Hook. F. } \\
\text { ex S. Moore }\end{array}$ & Ipê-amarelo & 1 & $\mathrm{~N}$ \\
\hline Chrysobalanaceae & Licania tomentosa (Benth.) Fritsch & Oiti & 1 & $\mathrm{~N}$ \\
\hline Combretaceae & Terminalia catappa L. & Castanhola & 1 & $\mathrm{E}$ \\
\hline \multirow{4}{*}{ Fabaceae } & Clitoria fairchildiana R.A. Howard & Sombreiro & 1 & $E$ \\
\hline & Delonix regia (Bojer ex Hook.) Raf. & Flamboyant & 1 & $\mathrm{E}$ \\
\hline & Inga laurina (Sw.) Willd. & Inga & 1 & $\mathrm{~N}$ \\
\hline & Andira parvifolia Mart. ex Benth. & Alvineira & 1 & $\mathrm{~N}$ \\
\hline Malvaceae & $\begin{array}{l}\text { Theobroma grandiflorum (Willd. ex Spreng.) K. } \\
\text { Schum. }\end{array}$ & Cupuaçu & 1 & $\mathrm{~N}$ \\
\hline Moraceae & Ficus benjamina L. & Ficus & 1 & $E$ \\
\hline \multirow{3}{*}{ Myrtaceae } & Syzygium malaccense (L.) Merr. \& L.M. Perry & Jambeiro & 1 & $\mathrm{E}$ \\
\hline & Syzygium cumini (L.) Skeels & Ameixeira & 1 & $\mathrm{E}$ \\
\hline & Psidium guajava L. & Goiabeira & 1 & $\mathrm{E}$ \\
\hline Rubiaceae & Genipa americana L. & Genipapo & 1 & $\mathrm{~N}$ \\
\hline
\end{tabular}

Corroborou-se os resultados de Gomes et al. (2016) que em seu estudo com a composição florística da Praça Nossa Senhora da Conceição, na zona sul da cidade de Macapá, constataram também que a família Fabaceae obteve maior destaque em número de espécies (sete espécies), seguidas das famílias Anacardiaceae, Arecaceae e Bignoniaceae que apresentaram três espécies cada. Teixeira et al. (2016) também encontraram maior número de espécies da família Fabaceae na arborização da Praça Camilo Mércio, na cidade de São Gabriel-RS. O fato da família Fabaceae ser muito representativa na arborização urbana está ligado ao seu grande número de espécies, cerca de 18.000 e mais de 600 gêneros, estando amplamente distribuída nos neotrópicos (MOURÃO; KARAM; SILVA, 2011)

Embora a família Arecaceae tenha se igualado com a Fabaceae em número de espécies, aquela se limitou mais ao interior da praça, tendo um valor mais ornamental. As espécies arbóreas das famílias Fabaceae, Anacardiaceae e Myrtaceae estavam mais distribuídas no calçamento da praça, proporcionando sombra (com suas copas amplas) para quem passa pelo calçamento público. De acordo Joly (2002), a família Arecaceae é 
representada pelas palmeiras, possuindo um grande valor estético agregado as suas espécies, valor este que a muitos séculos é utilizado no paisagismo de praças e jardins públicos.

Quanto à origem fitogeográfica das espécies inventariadas, os resultados (Tabela 1) demonstraram que do total de 19 espécies encontrada na arborização, 10 espécies são exóticas (representando 53\%) e nove espécies são nativas (representando 47\%).

A elevada utilização de espécies exóticas na arborização de áreas verdes urbanas está atribuída em parte a um reflexo de tendências paisagísticas anteriores, pois sob o ponto de vista estético, simplesmente é mais fácil encontrar espécies de grande beleza distribuídas por todo mundo, do que somente em um espaço geográfico ou formação vegetal restrita. Também há um evidente desconhecimento por parte da população e órgãos governamentais acerca da riqueza e utilização de espécies da flora nativa, associado a falta de planejamento e dificuldade na obtenção de mudas de espécies da flora regional. (LINDENMAIER; SANTOS, 2008). Blum, Borgo e Sampaio (2008) discorrem que as espécies exóticas podem afetar diretamente a biodiversidade, a economia e a saúde humana. Os autores ressaltam que essas espécies ocupam o segundo lugar na lista das causas de extinções das espécies nativas. A dominância de espécies exóticas na arborização de praças é um problema enfrentado em várias cidades do Brasil (TEIXEIRA et al., 2016; KRAMER; KRUPEK, 2012; SOUZA et al., 2011).

\section{Parâmetros fitossociológicos}

A espécie que apresentou maior número de indivíduos foi a Euterpe oleracea (86 indivíduos) o que representa $35,7 \%$ do total de indivíduos amostrados, seguida das espécies: Mangifera indica com 11,6\% (28 indivíduos); Clitoria fairchildiana 10,8\% (26 indivíduos); Cocos nucifera e Andira parvifolia com 7,5\% cada (18 indivíduos cada); e Tabebuia aurea e Syzygium malaccense com 4,1\% cada (10 indivíduos cada) (Figura 2). Em relação aos parâmetros fitossociológicos (Tabela 2), foi encontrada área basal total de $24,58 \mathrm{~m}^{2}$. As espécies com maior área basal foram: Clitoria fairchildiana $\left(8,73 \mathrm{~m}^{2}\right)$, Mangifera indica $\left(6,77 \mathrm{~m}^{2}\right)$ e Andira parvifolia $\left(2,03 \mathrm{~m}^{2}\right)$. As espécies que apresentaram maiores densidades relativas foram: Euterpe oleracea (35,83\%), Mangifera indica (11,67\%) e Clitoria fairchildiana (10,83\%). Com relação a dominância relativa, as espécies que melhor se destacaram nesse item foram: Clitoria fairchildiana (35,52\%), Mangifera indica (27,54\%) e Andira parvifolia (8,26\%). As três espécies que obtiverem maior índice de valor de cobertura foram: Clitoria fairchildiana (46,35\%), Mangifera indica (39,20\%) e Euterpe oleracea (36,94\%). A composição florística da praça Floriano Peixoto não é diversificada, conforme apresentou o índice de Shannon baixo $(0,98)$. 


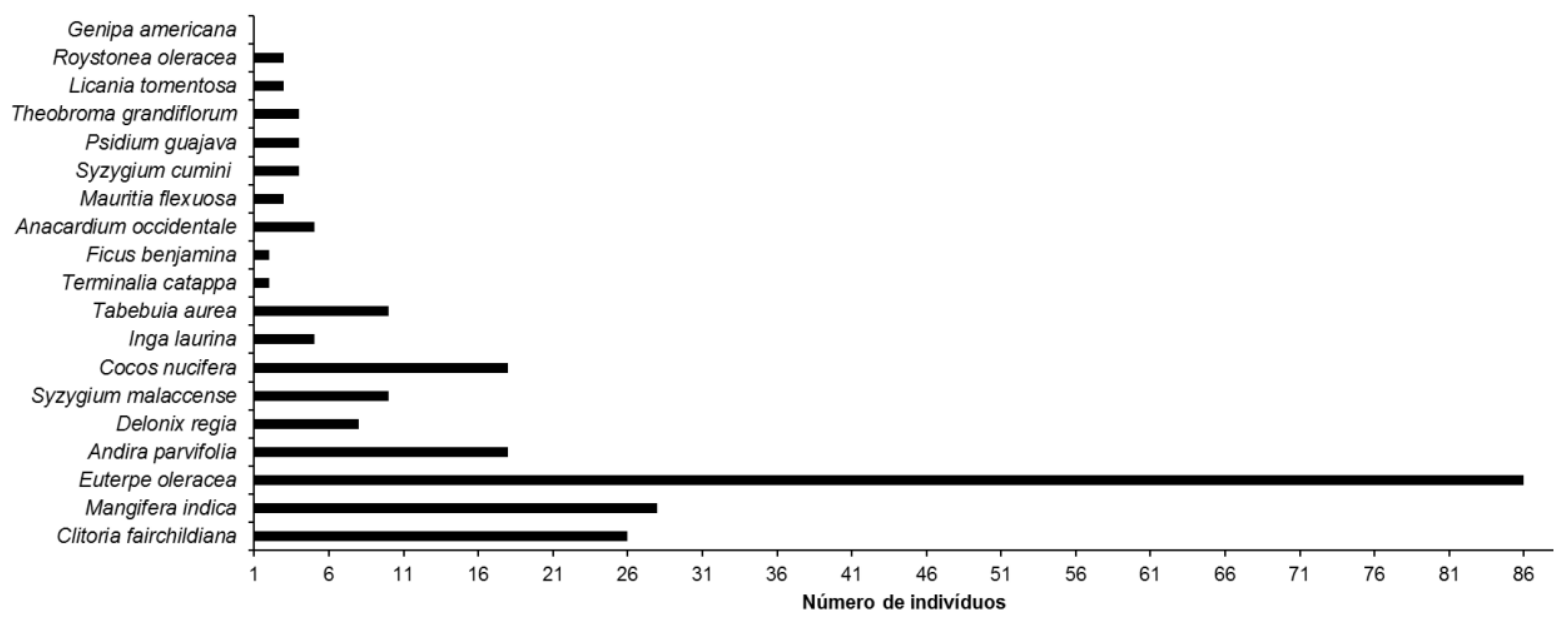

Figura 2. Número de indivíduos por espécie na composição florística da Praça Floriano Peixoto, Macapá-AP

Figure 2. Number of individuals for species in the floristic composition of Floriano Peixoto square, Macapá-AP

Tabela 2. Parâmetros fitossociológicos da composição florística da Praça Floriano Peixoto, Macapá-AP Table 2. Phytosociological parameters of the floristic composition of Floriano Peixoto square, Macapá-AP

\begin{tabular}{lccccc}
\hline Espécie & № indivíduos & Área basal & DR & DoR & IVC \\
\hline Anacardium occidentale & 5 & 0,25 & 2,08 & 1,02 & 3,10 \\
Andira parvifolia. & 18 & 2,03 & 7,50 & 8,26 & 15,76 \\
Clitoria fairchildiana & 26 & 8,73 & 10,79 & 35,52 & 46,35 \\
Cocos nucifera & 18 & 0,06 & 7,50 & 0,25 & 7,75 \\
Delonix regia & 8 & 1,76 & 3,33 & 7,15 & 10,48 \\
Euterpe oleracea & 86 & 0,27 & 35,83 & 1,11 & 36,94 \\
Ficus benjamina. & 2 & 0,66 & 0,83 & 2,68 & 3,52 \\
Genipa americana & 1 & 0.15 & 0,42 & 0,60 & 1,02 \\
Inga laurina & 5 & 1.05 & 2,08 & 4,27 & 6,36 \\
Licania tomentosa & 3 & 0.10 & 1,25 & 0,40 & 1,65 \\
Mangifera indica & 28 & 6.77 & 11,67 & 27,54 & 39,20 \\
Mauritia flexuosa & 3 & 0,37 & 1,25 & 1,53 & 2,78 \\
Psidium guajava & 4 & 0,001 & 1,67 & 0,004 & 1,67 \\
Roystonea oleracea & 3 & 0,06 & 1,25 & 0,24 & 1,49 \\
Syzygium cumini & 4 & 0,004 & 1,67 & 0,02 & 1,68 \\
Syzygium malaccense & 10 & 1,12 & 4.17 & 4,57 & 8,74 \\
Tabebuia aurea & 10 & 0,50 & 4,17 & 2,01 & 6,18 \\
Terminalia catappa & 2 & 0,70 & 0,83 & 2,83 & 3,67 \\
Theobroma grandiflorum & 4 & 0,001 & 1,67 & 0,003 & 1,67
\end{tabular}

Legenda: DR = Densidade Relativa; DoR = Dominância Relativa; IVC = Índice de Valor de Cobertura 
O fato da Euterpe oleracea obter o maior número de indivíduos em relação as demais espécies, pode ser explicado devido esta ser uma espécie nativa da Amazônia de fácil produção de mudas e rápido desenvolvimento em ambientes abertos. No entanto, de acordo com Santamour Júnior (1990), recomenda-se não exceder no plantio mais que $10 \%$ da mesma espécie, $20 \%$ de um mesmo gênero e $30 \%$ de uma família botânica, pois isso garante a diversidade florística e protege as espécies de pragas e doenças. Euterpe oleracea $(35,8 \%)$, Mangifera indica (11,7\%) e Clitoria fairchildiana (10,8\%) excederam em número de indivíduos de acordo com as recomendações de Santamour Júnior (1990).

Além do fato de haver baixa diversidade de espécies, há também a problemática da alta dominância, alto IVC e alta área basal de espécies exóticas como Clitoria fairchildiana e Mangifera indica. As espécies exóticas possuem alta capacidade de se adaptarem em ambientes não originários aos seus habitats e competem por recursos (luz, água e nutrientes) com as espécies nativas, inibindo o crescimento e o desenvolvimento das mesmas.

\section{Estrutura horizontal e vertical}

Quanto as classes diamétricas, os indivíduos foram agrupados em oito classes com amplitude entre as classes de $17,37 \mathrm{~cm}$, sendo que o menor DAP encontrado foi de 0,32 cm (da espécie Euterpe oleracea) e o maior foi de $139,17 \mathrm{~cm}$ (da espécie Clitoria fairchildiana). A arborização da praça Floriano Peixoto é composta em sua maioria por indivíduos jovens com maior número de indivíduos nas menores classes diamétricas (Figura 3).

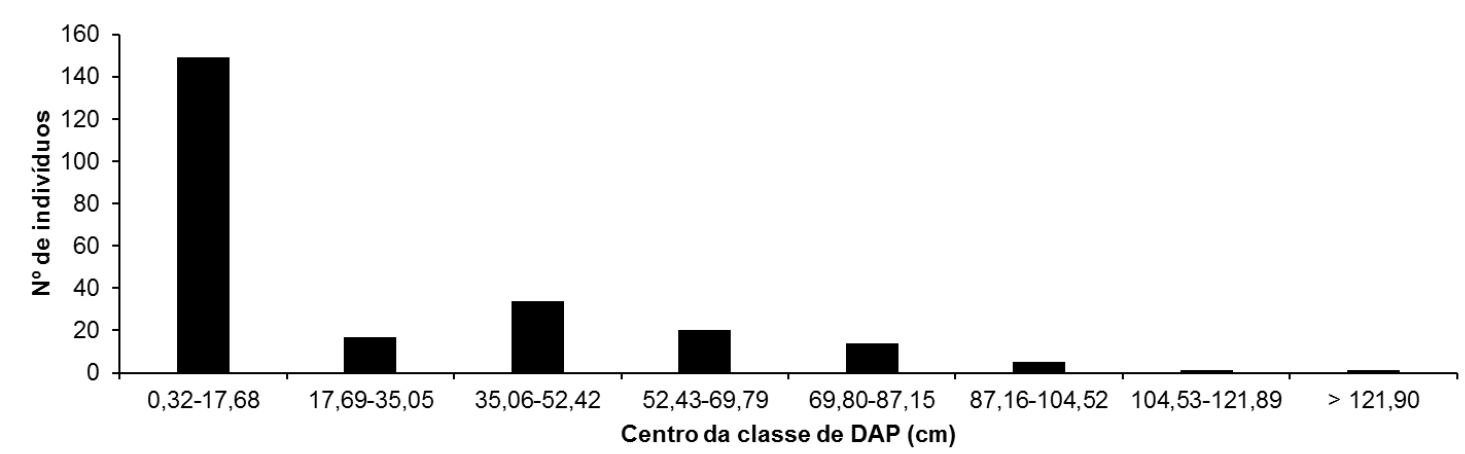

Figura 3. Distribuição diamétrica da composição arbórea da Praça Floriano Peixoto, Macapá- AP Figure 3. Diametric distribution of tree composition of Floriano Peixoto square, Macapá-AP

A conformação de "J invertido" na estrutura diamétrica está mais relacionada a composição florística, ou seja, com o grande número de indivíduos de Euterpe oleracea e devido ao seu pequeno valor de DAP. Outro fato que justifica o grande número de indivíduos nas primeiras classes diamétricas é o processo de dispersão das espécies. Todas as espécies 
da composição arbórea são frutíferas, um chamativo para os animais dispersores que encontram alimento e ajudam as árvores no processo de propagação da prole. A maioria dos indivíduos jovens encontrados foram de Euterpe oleracea que produz bastante quantidade de sementes e as mesmas são de fácil dispersão e propagação.

Constatou-se na estrutura vertical da composição florística que a maioria dos indivíduos estão concentrados na última classe de altura (Figura 4).

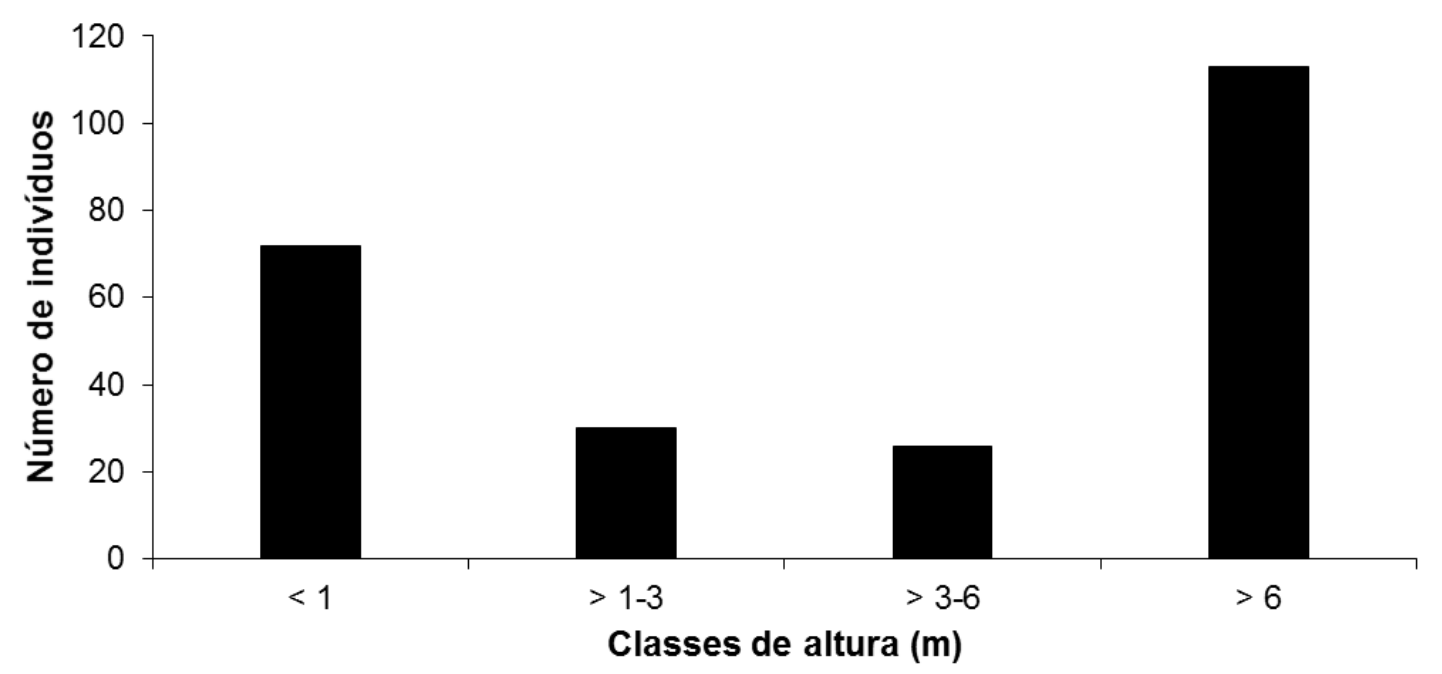

Figura 4. Classes de alturas da composição arbórea da Praça Floriano Peixoto, Macapá-AP Figure 4. Heights classes of tree composition of Floriano Peixoto square, Macapá-AP

Assim, o porte dos exemplares encontrados na praça demonstra que a sua arborização é composta por árvores de grande porte. Isso indica que a idade de tais exemplares arbóreos presentes na praça é relativamente avançada. Os resultados encontrados para a praça Floriano Peixoto diferenciam-se do estudo de Gomes et al. (2016) realizado na praça Nossa Senhora da Conceição (mesma cidade e bairro). Os autores constataram que a maioria dos indivíduos estava nas menores classes de altura. Esta diferença estar relacionada à renovação do plantio de indivíduos realizado na praça Nossa Senhora da Conceição ou pelo mau planejamento florístico.

\section{Aspectos fitossanitários}

No diagnóstico fitopatológico, a maioria dos indivíduos $(90,46 \%)$ estavam isentos, aparentemente, de alguma doença ou de algum organismo que pudesse prejudicar o desenvolvimento natural das espécies. Apenas 5,81\% dos indivíduos apresentaram cupins (no tronco, galhos ou na copa), 2,49\% apresentaram tronco oco, $0,83 \%$ estavam com fungos (principalmente os indivíduos jovens de Tabebuia aurea que estavam com ferrugens em suas folhas) e um indivíduo de Terminalia catappa apresentou erva-de-passarinho em sua copa 
estratificada (Figura 5). De acordo com o diagnóstico fitossanitário, as constrições da praça Floriano Peixoto são consideradas satisfatórias.

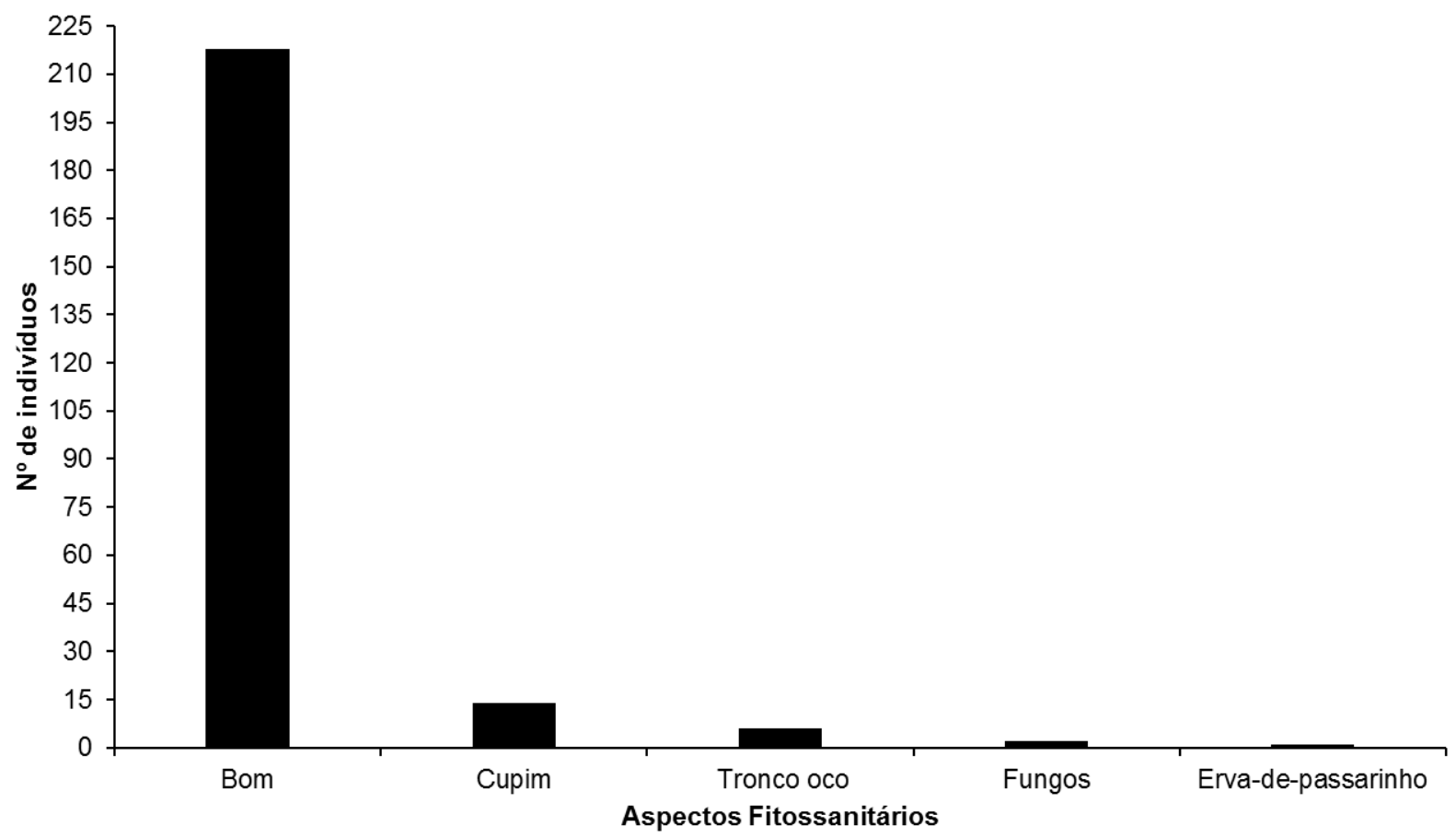

Figura 5. Situação fitossanitária da composição florística da Praça Floriano Peixoto, Macapá-AP

Figure 5. Phytosanitary situation of floristic composition of Floriano Peixoto square, Macapá-AP

Segundo Sousa et al. (2014), o manejo fitossanitário adequado das árvores é fundamental para a prevenção de problemas fitossanitários, pois o ataque de um fitopatógeno pode dizimar uma grande quantidade de indivíduos. Os resultados deste estudo corroboram com os obtidos por Rodolfo Júnior et al. (2008), quando avaliaram as condições das árvores em áreas verdes urbanas em bairros da cidade de Pombal-PB, encontrando cerca de 40 a $50 \%$ da arborização em bom estado de fitossanidade.

\section{Cinta de proteção e área de desenvolvimento radicular e basal}

Dentre os 240 indivíduos, 45 indivíduos estavam plantados ao longo do calçamento da praça. Sendo assim, levou-se em consideração na análise da estrutura de cinta de proteção e da área de desenvolvimento basal apenas esses indivíduos. Das espécies que estavam no calçamento nenhuma apresentava cinta de proteção. Com relação a área de desenvolvimento basal e radicular, $20 \%$ dos indivíduos apresentavam área suficiente para o desenvolvimento e o restante, $80 \%$ dos indivíduos, apresentava área insuficiente. 
A cinta de proteção é uma mureta de concreto ou de tijolo que exerce função fundamental na proteção do sistema radicular da planta, que se encontra no calçamento, contra agentes químicos como água de lavagem, soluções ácidas, gorduras, etc. Quanto à área de crescimento, segundo Paiva e Gonçalves (2002) é fundamental para o desenvolvimento dos indivíduos arbóreos, pois esta irá garantir a infiltração da água e o crescimento em diâmetro do vegetal, bem como pode garantir a proteção contra ações abióticas. A função principal desta área é proporcionar melhor drenagem das águas pluviais, de irrigação e, caso necessário, adubações complementares.

\section{Plantas ornamentais (composição florística)}

Neste estudo, foram encontradas nove famílias de espécies ornamentais, divididas em 11 gêneros e 12 espécies (Tabela 3). As famílias Apocynaceae, Euphorbiaceae e Rubiaceae obtiveram maior número de espécies (duas espécies cada).

Tabela 3. Espécies ornamentais presentes na Praça Floriano Peixoto, Macapá-AP

Table 3. Ornamental species present in Floriano Peixoto square, Macapá-AP

\begin{tabular}{llll}
\hline \multicolumn{1}{c}{ Família botânica } & \multicolumn{1}{c}{ Espécie } & \multicolumn{1}{c}{ Nome comum } & Origem \\
\hline Amaranthaceae & Alternanthera ficoidea (L.) P. Beauv. & Apaga-fogo & $\mathrm{N}$ \\
\hline \multirow{2}{*}{ Apocynaceae } & Allamanda cathartica L. & Alamanda & $\mathrm{N}$ \\
& Allamanda blanchetii A. DC. & Alamanda-rosa & $\mathrm{N}$ \\
\hline Asparagaceae & Agave angustifolia Haw. & Agave & $\mathrm{E}$ \\
\hline Clusiaceae & Clusia fluminensis Planch. \& Triana & Clúsia & $\mathrm{N}$ \\
\hline \multirow{2}{*}{ Euphorbiaceae } & Codiaeum variegatum (L.) Rumph. ex A. & Cróton & $\mathrm{E}$ \\
& Juss. & & $\mathrm{E}$ \\
\hline Heliconiaceae & Euphorbia ingens E. Mey. ex Boiss. & Cacto-candelabro & $\mathrm{E}$ \\
\hline Malvaceae & Heliconia rostrata Ruiz \& Pav. & Papagaio & $\mathrm{E}$ \\
\hline \multirow{2}{*}{ Rubiaceae } & Malvaviscus arboreus Cav. & Amapola & $\mathrm{E}$ \\
& Mussaenda erythrophylla Schumach. \& & Mussaenda-rosa & \\
\hline Verbenaceae & Thonn. & & $\mathrm{E}$ \\
\hline
\end{tabular}

As espécies ornamentais foram encontradas em arredores de canteiros servindo como cercas vivas, sendo que a maioria das plantas ornamentais encontradas na praça são de origem exótica. De acordo com Lima, Kreutz e Pereira (2016), isto está ligado possivelmente em virtude dessas espécies se adaptarem bem ao clima tropical, portanto se mantendo no 
ambiente e, também, as escolhas dessas espécies para inserção no processo de paisagismo ocorre devido ao pouco conhecimento ecológico proporcionado por um plano de paisagismo inadequado. Segundo os mesmos autores, a solução deste problema está na obrigação dos órgãos públicos em fiscalizar e interpor medidas que sejam efetivadas em um plano de manejo adequado no plantio de espécies adaptadas para cada região.

\section{CONCLUSÕES}

A praça Floriano Peixoto apresenta baixa diversidade florística $\left(H^{\prime} \quad 0,98\right)$ e maior número de espécies exóticas, isso sugere medidas que visem o planejamento adequado da diversificação florística desta praça e de outras praças da cidade de Macapá, já que os resultados deste trabalho podem servir de guia para o planejamento adequado da arborização.

A estrutura horizontal da arborização é composta de indivíduos jovens, evidenciando que há um programa de plantio e reposição de plântulas na praça (fato comprovado pelo plantio recente de seis exemplares de Tabebuia aurea). Deve-se haver um controle dos indivíduos que germinam espontaneamente e de daqueles indivíduos que brotam de galhos e raízes, para que não ocorra a dominância de uma única espécie (neste caso Euterpe oleracea). As condições para o desenvolvimento das espécies no calçamento, mostrou-se bastante precária devido não haver manutenção da estrutura de cinta de proteção (estrutura danificada pelo tempo e pelas as raízes das árvores) e do calçamento da praça. O plantio de espécies arbóreas no calçamento demanda planejamento e pesquisa, pois cada espécie tem sua característica de crescimento e desenvolvimento.

\section{REFERÊNCIAS}

ALCANTARA, M. A. R.; VAZQUEZ, G. H. Caracterização paisagística e da frequência de usuários de duas praças centrais de Caraguatatuba/SP. Revista da Sociedade Brasileira de Arborização Urbana, Piracicaba, v. 10, n. 3, p. 38-59, 2016.

APG III - The Angiosperm Phylogeny Group. An update of the Angiosperm Phylogeny Group classification for the orders and families of flowering plants: APG III. Botanical Journal of the Linnean Society, London, v. 161, n. 2, p. 105-121, 2009.

BARBOSA, L. A.; LOPES, C. G. R.; LOPES, W. G. R. Levantamento das espécies vegetais das praças de São João dos Patos-MA. Revista da Sociedade Brasileira de Arborização Urbana, Piracicaba, v. 10, n. 1, p. 19-29, 2015. 
BLUM, C. T.; BORGO, M.; SAMPAIO, A. C. F. Espécies exóticas invasoras na arborização de vias públicas de Maringá-PR. Revista da Sociedade Brasileira de Arborização Urbana, Piracicaba, v. 3, n. 2, p. 78-97, 2008.

GOMES, E. M. C.; RODRIGUES, D. M. S.; SANTOS, J. T.; BARBOSA, E. J. Análise qualiquantitativa da arborização de uma praça urbana do Norte do Brasil. Nativa, Sinop, v. 4, n. 3, p. 179-186, 2016.

JOLY, A. B. Botânica: Introdução à Taxonomia Vegetal. São Paulo: Companhia Editora Nacional, 2002. 424p.

KRAMER, J. A.; KRUPEK, R. A. Caracterização florística e ecológica da arborização de praças públicas do município de Guarapuava, PR. Revista Árvore, Viçosa, v. 36, n. 4, p. 647-658, 2012.

LACERDA, M. A.; SANTANA S. F.; COSTA, J. P. M.; SOUZA M. R.; MEDEIROS, E. N.; CARVALHO, J. A.; SILVA, Z. L. Levantamento florístico da arborização urbana nas principais vias públicas do município de Boa Ventura-PB. Revista Brasileira de Gestão Ambiental, Pombal, v. 7, n. 4, p. 12-16, 2013.

LIMA, J. P.; KREUTZ, C.; PEREIRA, O. R. Levantamento florístico das espécies utilizadas na arborização de praças no município de Nova Xavantina-MT. Revista da Sociedade Brasileira de Arborização Urbana, Piracicaba, v. 10, n. 3, p. 60-72, 2016.

LINDENMAIER, D. S.; SANTOS, N. O. Arborização urbana das praças de Cachoeira do SulRS-Brasil: fitogeografia, diversidade e índice de áreas verdes. Pesquisas, Série Botânica, São Leopoldo, n. 59, p.307-320, 2008.

MOURÃO, S. A.; KARAM. D.; SILVA, J. A. Uso de leguminosas no semiárido mineiro. Sete Lagoas: Embrapa, 2011.91p.

OLIVEIRA, A. S.; SANCHES, L.; MUSIS, C. R.; NOGUEIRA, M. C. J. A. Benefícios da arborização em praças urbanas. Revista Eletrônica em Gestão, Educação e Tecnologia Ambiental, Santa Maria, v. 9, n. 9, p. 1900-1915, 2013.

PAIVA, H. N.; GONÇALVES, W. Florestas urbanas: planejamento para a qualidade de vida. Viçosa: Aprenda Fácil, 2002. 177p.

RODOLFO JÚNIOR, F.; MELO, R. R.; CUNHA, T. A.; STANGERLIN, D. M. Análise da arborização urbana em bairros da cidade de Pombal no estado da Paraíba. Revista da Sociedade Brasileira de Arborização Urbana, Piracicaba, v. 3, n. 4, p. 3-19, 2008.

SANTAMOUR JÚNIOR, F. S. Trees for urban planting: diversity uniformity, and common sense. In: METRIA CONFERENCE, 7., 1990, Lisle. Proceedings...Lisle: 1990. p. 57-66

SANTOS, A. F.; JOSÉ, A. C.; SOUSA, P. A. Fitossociologia e diversidade de espécies arbóreas das praças centrais do município de Gurupi-TO. Revista da Sociedade Brasileira de Arborização Urbana, Piracicaba, v. 8, n. 4, p. 36-46, 2013.

SANTOS, N. R. Z.; TEIXEIRA, I. F. Arborização de vias públicas: Ambiente x vegetação. Porto Alegre: Pallotti, 2001. 135p.

SILVA, J. A. A.; NETO, F. P. Princípios básicos de dendrometria. Recife: UFRPE, 1979. $191 \mathrm{p}$. 
SOUZA, A. L.; FERREIRA, R. A.; MELLO, A. A.; PLÁCIDO, D. R.; SANTOS, C. Z. A.; GRAÇA, D. A. S.; JÚNIOR, P. P. A.; BARRETTO, S. S. B.; DANTAS, J. D. M.; PAULA, J. W. A.; SILVA, T. L.; GOMES, L. P. S. Diagnóstico quantitativo e qualitativo da arborização das praças de Aracaju, SE. Revista Árvore, Viçosa, v. 35, n. 6, p. 1253-1263, 2011.

SOUSA, R. D. C.; AGUIAR, O. D.; SILVA, L.; SILVA, L.; MARRA, R. Avaliação qualiquantitativa da arborização na praça Agostinho Nohama, bairro Lauzane Paulista, São PauloSP. Revista da Sociedade Brasileira de Arborização Urbana, Piracicaba, v. 9, n. 1, p. 92107, 2014.

TAVARES, J. P. N. Características da climatologia de Macapá-AP. Caminhos de Geografia, Uberlândia, v. 15, n. 50, p. 138-151, 2014.

TEIXEIRA, I. F.; FIGUEIREDO, F. M.; TABORDA, I. G. R.; SOARES, L. M. Análise fitossociológica da praça Camilo Mércio no centro histórico de São Gabriel, RS. Revista da Sociedade Brasileira de Arborização Urbana, Piracicaba, v. 11, n. 1, p. 01-13, 2016. 